\title{
Cutaneous leishmaniasis in French Guiana: revising epidemiology with PCR-RFLP
}

\author{
Stephane Simon 1,3, Mathieu Nacher ${ }^{1,2}$, Bernard Carme ${ }^{1,3}$, Celia Basurko $^{2}$, Amaury Roger ${ }^{2}$, Antoine Adenis 2 , \\ Marine Ginouves ${ }^{1,3^{*}}$ (iD, Magalie Demar ${ }^{1,3}$ and Pierre Couppie , $^{1,3,4}$
}

\begin{abstract}
Background: The development of polymerase chain reaction-restriction fragment length polymorphism (PCR-RFLP) technique for species identification among patients presenting leishmaniasis allowed to better determine the main circulating species in French Guiana.

Methods: A descriptive study of the Leishmania species was identified, and their spatiotemporal distribution was conducted using patient records between 2006 and 2013, with 1017 new cases of leishmaniasis diagnosed. Identification was realized by PCR-RFLP on 745 cases.

Results: The average proportions for different species were $86.2 \%$ for Leishmania (Vianna) guyanensis; 9.7\% for Leishmania (Vianna) braziliensis; 2.8\% for Leishmania (Leishmania) amazonensis; and 1.3\% for Leishmania (Vianna) lainsoni, and no case of Leishmania (Vianna) naiffi was identified. Over this period, the proportion of cases due to $L$. $(V$.) braziliensis seemed to increase from 8.9\% in 2006 to 13.0\% in 2013 notably near the gold mining zones.

Conclusions: The use of molecular tools has transformed the view of the local epidemiology of cutaneous leishmaniasis in French Guiana.
\end{abstract}

Keywords: Cutaneous leishmaniasis, Leishmania braziliensis, Epidemiology, PCR-RFLP, French Guiana

\section{Background}

Considered like a "neglected tropical disease" by the World Health Organization [1], cutaneous leishmaniasis is a well-known parasitosis firmly established in South America [2-4]. In French Guiana, leishmaniasis was described for the first time in 1954 [5]. The annual incidence rate was estimated between 15 and 20 new cases per 10,000 inhabitants between 1979 and 2012 [6-8]. Five human Leishmania species have been described in French Guiana: Leishmania (Viannia) guyanensis, Leishmania (Viannia) braziliensis, Leishmania (Leishmania) amazonensis, Leishmania (Viannia) lainsoni, and Leishmania (Viannia) naiffi $[9,10]$. These species all have a cutaneous tropism. The previous descriptions

\footnotetext{
* Correspondence: marine.ginouves@univ-guyane.fr

${ }^{1}$ Equipe EA3593 Ecosystemes Amazoniens et Pathologie Tropicale, Université de la Guyane, Campus Saint Denis, Avenue d'Estrées, 97300 Cayenne, French Guiana

${ }^{3}$ Laboratoire Associé - Centre National de Référence Leishmania, Laboratoire Hospito-Universitaire de Parasitologie Mycologie, Cayenne General Hospital, 97300 Cayenne, French Guiana

Full list of author information is available at the end of the article
}

of the local epidemiology in French Guiana suggested that $L$. (V.) guyanensis is by far the predominant species [11] most frequently responsible for localized cutaneous presentations, but it may at times lead to diffuse presentations [12]. Leishmania (Vianna) braziliensis is a more virulent species that is potentially responsible for mucous involvement (nose, mouth, and throat). In French Guiana, there was no case caused by $L$. (V.) braziliensis described before 1986, and only nine cases have been diagnosed between 1987 and 1996 [13]. However, when these studies were undertaken, cultures were rarely performed and only when the patient's lesion did not heal or show some clinical particularities.

The development in 2005 of a polymerase chain reaction-restriction fragment length polymorphism (PCRRFLP) technique, by the parasitology-mycology university laboratory in Cayenne [14], allowed a more systematic species identification among patients presenting leishmaniasis lesions.

In this context, the objective of this paper is to update the epidemiological situation of leishmaniasis in 
French Guiana to monitor the evolution of Leishmania species and, more particularly, the emergence of $L$. braziliensis [15].

\section{Methods \\ Objectives}

This study aims to describe the spatiotemporal distribution of human cases of cutaneous leishamaniasis from the cohort of the parasitology laboratory of Cayenne General Hospital (LHUPM) in French Guiana between 1 January 2006 and 31 December 2013. The identification of Leishmania species corresponded to the surveillance and alert mission of the National Reference Center (CNR) of Leishmania for which the LHUPM constitutes a local relay.

\section{Type of study}

The study was observational, retrospective, and monocentric.

\section{Study population}

The study population was the patients in consultation for a suspicion of leishmaniasis at the LHUPM and in the health centers of the interior (administratively attached to Cayenne General Hospital) between 1 January 2006 and 31 December 2013. New cases were defined as cases without a history of leishmianasis in the past 12 months. Diagnosis was confirmed by the presence of Leishmania parasites on microscopic examination of May-Grünwald Giemsa-colored skin smears, and/or by a positive culture on RPMI culture medium, and/or by the detection of Leishmania DNA by PCR. During this period, 1017 cases were detected and species identification has been possible on 745 cases. This difference is explained by the fact that for some patients, we only had a stained slide, or in others, the PCR-RFLP did not allow identification (insufficient Leishmania DNA quantity).

\section{Study variables}

The study variables were collected from standardized medical forms which are part of medical records both at the dermatology and the parasitology departments of Cayenne General Hospital. These variables were the following: consultation date, contamination location, profession, geographic origin, age, sex, and species of Leishmania identified. Presumptive contamination site was declared by the patient during the consultation. For cases diagnosed in health centers, the location was the township of the health center, unless specified otherwise.

\section{Leishmania identification}

The species identification was performed by the University laboratory of Cayenne using a PCR-RFLP technique in collaboration with the LHUPM [14]. Briefly, DNA was extracted using DNeasy Tissue and Blood Kit (Qiagen, Hilden, Germany), according to the manufacturer's instructions. Then, the extracted DNA was amplified with RPOF2 (5'-AGAACATGGGCGGCC$3^{\prime}$ ) and RPOR2 (5'CGAGGGTCACGTTCTTG-3') primers (Eurogentec) which target a 615 -bp region of the RNA polymerase II gene. The PCR product was digested with TspRI or HgaI (New England Biolabs). The entire reaction mixture was then analyzed by electrophoresis in a $2 \%$ agarose gel containing ethidium bromide. The resulting profile was species-specific. This identification was performed from the culture of the biopsies taken during consultations at dermatology department. If the parasite has grown, the PCR-RFLP was performed on the culture. If there was not growth, the PCR-RFLP was performed on the biopsy.

\section{Analysis}

First, the analysis concerned the whole study population in order to conduct a quality control of the data using coherence tests and eventual queries to go back to the patient records to clean the data. After this, comparisons between proportions were performed using the chisquare test and the linear chi-square test for trend in order to identify any temporal trends. Data were analyzed with STATA 12 (College Station, Texas).

The analysis described the appropriate position and dispersion measures for quantitative variables (mean and standard deviation for Gaussian variables, median and interquartile range (IQR) for non-Gaussian variables). For qualitative variables, frequencies and proportions were reported. The calculation of the annual incidence was performed between 2006 and 2013 from the data of dermatology and the parasitology departments. Cases were reported to the total population of French Guiana using the annual data from the National Institute for Statistics and Economic Evaluation's (INSEE) censuses and projections.

\section{Ethics statement}

The study was retrospective. All patients were informed (leaflets, posters in several local languages) that data and analysis results may be used in research, and scientific publications, and that they had a right to refuse.

\section{Results}

Between 1 January 2006 and 31 December 2013, 1017 new cases of leishmaniasis were diagnosed for an average of 127 cases per year, with interannual variations between 96 and 160 cases per year. The annual incidence oscillated between 4.6 and 7.0 cases per 10,000 inhabitants with an average of 5.6 cases/year (Fig. 1). The median age of patients was 35 years ranging from 3 to 87 years of age $(\mathrm{IQR}=28-45)$, and the sex ratio was 


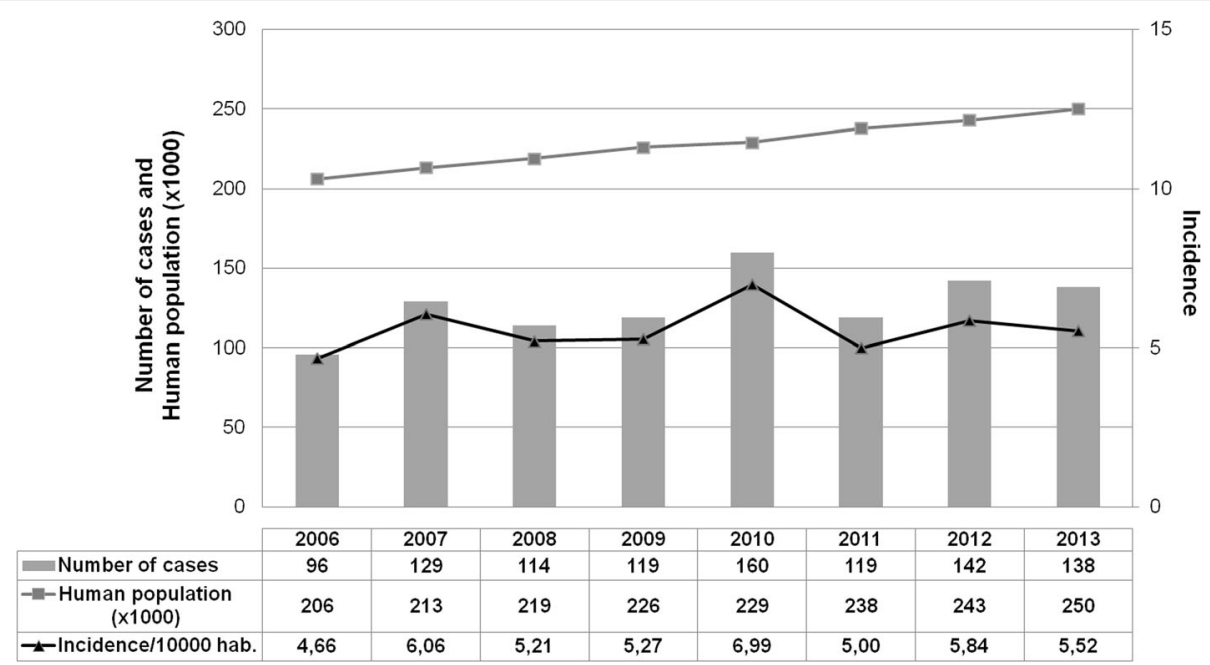

Fig. 1 Total number of leishmaniasis cases in French Guiana (2006-2013). The total number of cases $(n=1017)$ was in relation to the number of inhabitants. The incidence rate was calculated per 10,000 inhabitants and per year

4.5 (793 men/224 women). The theoretical date of infection was known in 525 cases $(51.6 \%)$. The median date of infection was 1 month before the consultation, ranging from 0.25 to 360 months (IQR $=1-2)$. The number of lesions was known in 568 cases (55.9\%). The median number was one lesion ranging from one to over 200 lesions $(\mathrm{IQR}=1-2)$.

Among infected patients, $39.6 \%$ had an outdoor professional occupation (29.9\% of gold miners, $22.8 \%$ of military, $14.1 \%$ of farmers, $11.4 \%$ of bricklayers, $9.2 \%$ of workers in the lumber industry); $43 \%$ had various urban or peri-urban professions; $15.3 \%$ were not employed; and $2.1 \%$ were pensioners. For $54.3 \%$ of patients, profession data was missing.

Concerning molecular diagnosis, 745 (73.3\%) Leishmania species identifications were performed. The difference is explained by the fact that sometimes we receive only MGGcolored skin smears and no biopsy, but also as PCR-RFLP on biopsy is trickier (quantity of Leishmania DNA too low). Figure 2 illustrates the evolution of the proportion of cases

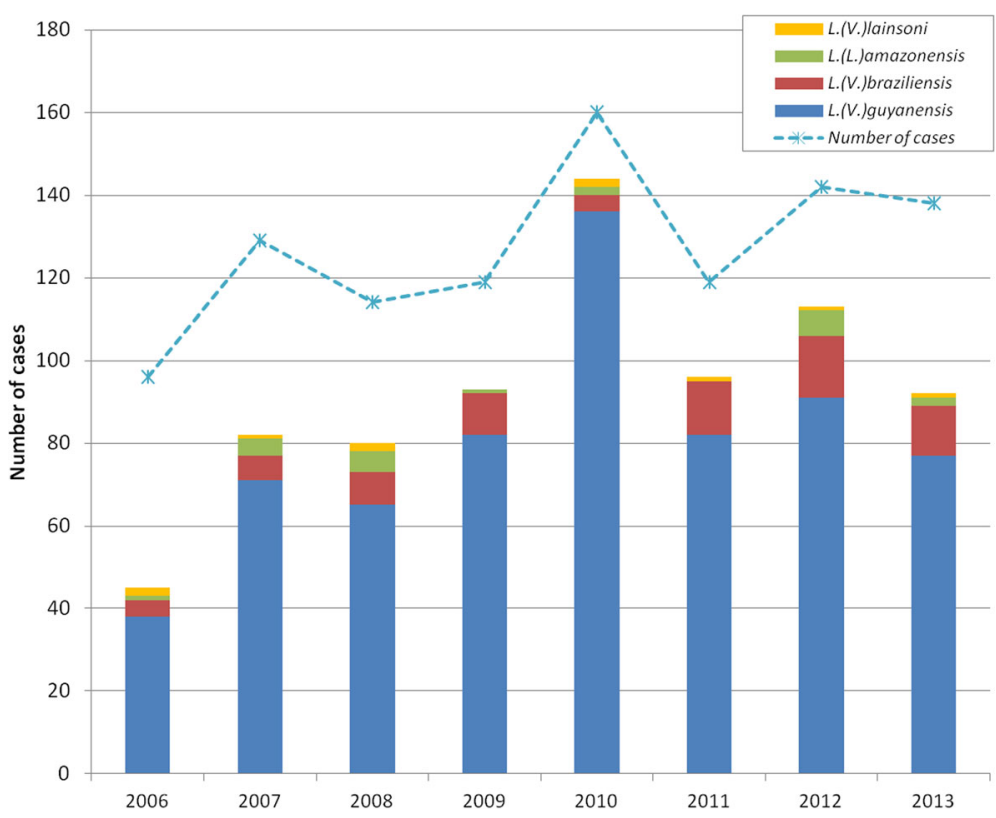

Fig. 2 Identification of leishmania species by PCR-RFLP method on 745 samples assessed between 2006 and 2013 
Table 1 Identification of Leishmania strain in French Guiana between 2006-2013.

\begin{tabular}{|c|c|c|c|c|}
\hline Year & $\begin{array}{l}\text { L. (V.) guyanensis } \\
N(\%)\end{array}$ & $\begin{array}{l}\text { L. (V.) braziliensis } \\
N(\%)\end{array}$ & $\begin{array}{l}\text { L. (L.) amazonensis } \\
N(\%)\end{array}$ & $\begin{array}{l}\text { L. (V.) lainsoni } \\
N(\%)\end{array}$ \\
\hline $2006(n=45)$ & $38(84.4)$ & $4(8.9)$ & $1(2.2)$ & $2(4.4)$ \\
\hline $2007(n=82)$ & 71 (86.6) & $6(7.3)$ & $4(4.9)$ & $1(1.2)$ \\
\hline $2008(n=80)$ & 65 (81.3) & $8(10.0)$ & $5(6.3)$ & $2(2.5)$ \\
\hline $2009(n=93)$ & $82(88.2)$ & $10(10.8)$ & $1(1.1)$ & $0(0)$ \\
\hline $2010(n=144)$ & $136(94.4)$ & $4(2.8)$ & $2(1.4)$ & $2(1.4)$ \\
\hline $2011(n=96)$ & $82(85.4)$ & $13(13.5)$ & $0(0)$ & $1(1.0)$ \\
\hline $2012(n=113)$ & $91(80.5)$ & $15(13.3)$ & $6(5.3)$ & $1(0.9)$ \\
\hline $2013(n=92)$ & 77 (83.7) & $12(13.0)$ & $2(2.2)$ & $1(1.1)$ \\
\hline Total $(n=745)$ & $642(86.2)$ & $72(9.7)$ & $21(2.8)$ & $10(1.3)$ \\
\hline
\end{tabular}

For each year, the number of cases per species is given in absolute value $(N)$ and percentage (\%)

by species. The average proportions were $86.2 \%$ for $L$. $(V$.) guyanensis; $9.7 \%$ for L. (V.) braziliensis; $2.8 \%$ for $L$. (L.) amazonensis; $1.3 \%$ for L. (V.) lainsoni; no case of $L$. (V.) naiffi leishmaniasis was identified, but the proportion of cases due to L. (V.) braziliensis increased from $8.9 \%$ in 2006 to $13.0 \%$ in 2013 (Table 1). Forty strains were sent to the National Reference Center for Leishmania in Montpellier (France) to confirm our diagnosis by multilocus enzyme electrophoresis (MLEE) and/or by sequencing of RNA polymerase II gene. Although L. (V.) panamensis, L. (L.) colombiensis, and $L$. (L.) venezuelensis are endemic in some countries in South America [16-18], these strains are not found in French Guiana. However, since 2007, the proportion of $L$. $(V$.) braziliensis has significantly increased (7.3 vs $13.3 \%, P=0.005)$. The decrease observed in 2010 may have been related to small numbers which increase the risk of extreme values. The linear trend however failed to reach statistical significance $(P=0.07)$.

The number of monthly cases diagnosed averaged over the 8 years of the study showed a seasonal pattern with a peak in January (23.3 cases) and a minimum in August (1.4 cases) (Fig. 3 ).

The geographical distribution of 689 cases $(67.7 \%)$ on the known presumptive contamination site showed that $15.4 \%$ was concentrated in the townships of Maripasoula, 9.3\% in Cacao, $7.7 \%$ in Regina, 6.8\% in Saül, and 5.8\% in Grand Santi. On their 689 cases with a known presumptive contamination sites, species identification was possible in 561 cases. These sites were grouped into four major areas (Fig. 4). The proportion of cases due to $L$. (V.) braziliensis was higher in areas where gold mines were located.

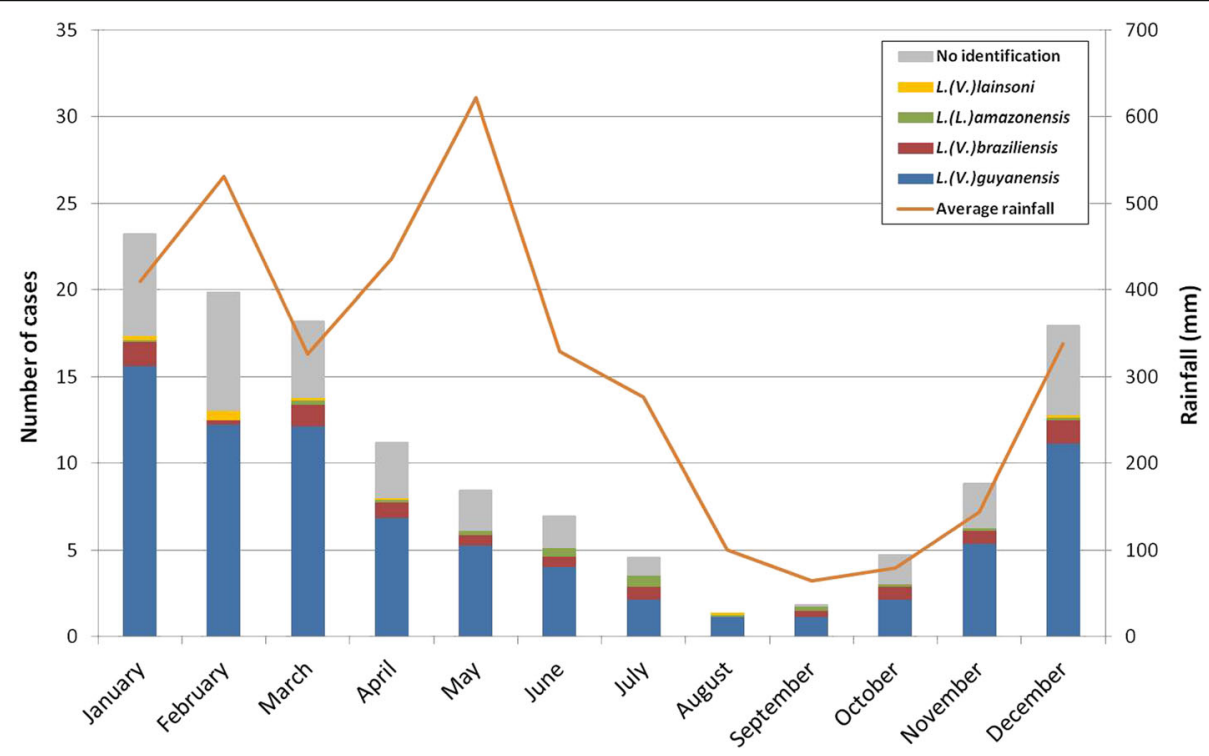

Fig. 3 Average number of leishmaniasis cases in relation to average rainfall per month (2006-2013) 


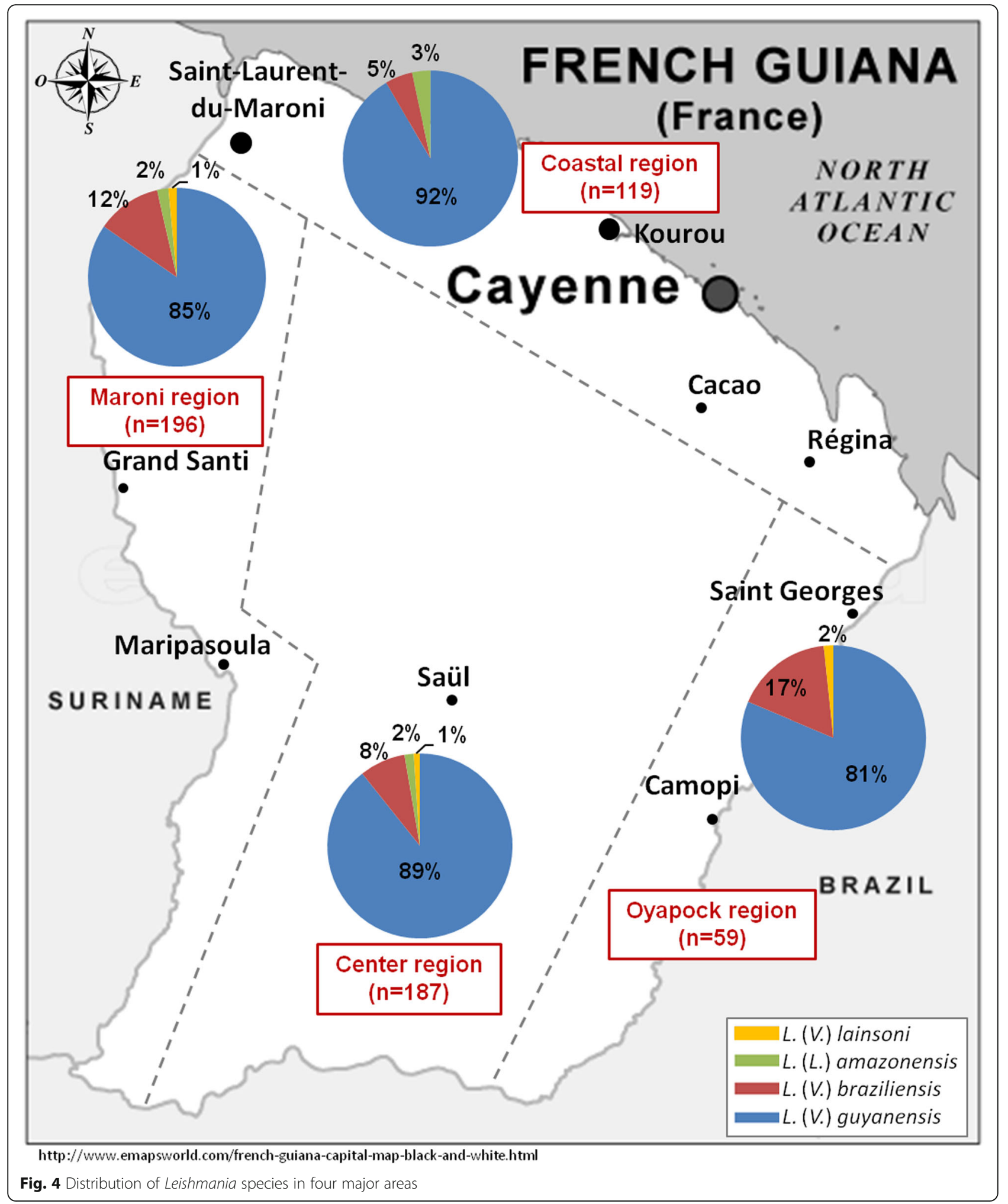

Nine cases involved mucosal lesions: six were due to $L$. (V.) guyanensis and three cases were due to $L$. $(V$.) braziliensis. The frequency of mucosal forms due to $L$. (V.) guyanensis was $0.9 \%$ and $4.2 \%$ for $L$. (V.) braziliensis.

\section{Discussion}

Data from the 1980s suggested that $L$. (V.) braziliensis did not circulate in French Guiana [19, 20]. The present results showed that this is not the case today. Moreover, 
during the study period, the specific incidence of $L .(V$. braziliensis globally seemed to increase linearly. The increase of the cases due to this species could be linked to the generalization of the species diagnosis that followed from the local development of an identification technique.

Indeed, before 2006, because of the difficulties of the transatlantic transport of samples and the delays of the isoenzymes technique, the search for the causative species was mostly motivated by an unusual presentation or an unfavorable evolution. It is thus probable that cases of $L$. (V.) braziliensis leishmaniasis with a simple common cutaneous uncomplicated presentation and evolution were not identified. This hypothesis underlines the interest of the exploitation of older biological collections, which could be suitable for species diagnosis by PCR-RFLP. Another hypothesis for the apparent increase of the proportion on $L$. (V.) braziliensis would be signs of an emerging problem. This hypothesis was reinforced by the apparent preponderance of cases near gold mining sites.

The incidence calculated in the present study (5.6 cases/10,000 inhabitants/year) was four to five times lower than the values reported in the literature $[6,7]$. This difference is explained by the fact that the number of cases of leishmaniasis remains stable while the population is growing rapidly (113,351 in 1990 to 250,109 in 2013). The information collected allowed us to establish a reliable indicator that shows a lower incidence during the 1990s, but a relatively stable incidence with regular seasonal variations, which still remains to be fully explained. The annual repartition of leishmaniasis diagnosis always follows a seasonal pattern as described elsewhere $[21,22]$, which underlines the probable influence of climate on the transmission of the parasite. The peak intensity of cases observed in 2010 may have been influenced by the El Niño phenomenon in 2009-2010 [23]. Studies have shown that this phenomenon has an impact on the increase of cases of leishmaniasis in South America [24-27]. Correlations between climatic variables, vector populations, and human contaminations have previously been described in neighboring countries [27-29]. However, local studies could be useful to complete the data with entomological studies and improve the understanding of cycles of leishmaniasis in French Guiana. It is not clear whether geographical distribution of the different Leishmania species is linked to different human populations or different vector populations with different competencies for different parasites.

\section{Conclusions}

The molecular study using PCR-RFLP confirms the presence of $L$. (V.) braziliensis in French Guiana [14] with a high proportion of cases than previously thought $10 \%$ rather than absent. The use of PCR-RFLP allows rapid identification of Leishmania strains. Without treatment, the risk for patients infected with $L$. $(V$.) braziliensis is to develop, in some cases, the mucocutaneous form of the disease. This precose identification allows a rapid management of the patients, which limits the appearance of the cutaneomucous forms. Furthermore, species identification will be further monitored as it is not clear that the proportion of $L$. (V.) braziliensis increases significantly in the context of intense gold mining or whether we are now seeing its real impact due to the recent introduction of the PCR-RFLP technique.

\section{Abbreviations}

IQR: Interquartile range; LHUPM: Laboratoire Hospitalo-Universitaire de Parasitologie et mycologie

\section{Acknowledgments}

We thank the members of the hospital who helped us in this study and Centre National de Référence des Leishmanioses (The French National Reference Center for Leishmania), Montpellier University Hospital, France, for the reference strains.

\section{Availability of data materials}

Data can be made available, but this would require specific CNIL approval.

\section{Authors' contributions}

SS and MD participated in the study design and implementation and contributed in writing the manuscript. MN participated in the study design and analysis and interpretation of the data and in writing the manuscript. BC participated in the study design and implementation. $C B, A R$, and $A A$ carried out the analysis and interpretation of the data. MG participated in the analysis and interpretation of the data and contributed in writing. PC participated in the study design and in the analysis and interpretation of the data. All authors read and approved the final manuscript.

\section{Competing interests}

The authors declare that they have no competing interests.

\section{Consent for publication}

All included patients were informed that if they participated in the study, the results would be published.

\section{Ethics approval and consent to participate}

All patients were informed about the study and agreed to participate. Ethical approval was given by the Cayenne Hospital ethical committee. The study was declared to the regulatory authority Commission Nationale Informatique et Libertés (CNIL) no. c4K1993279q.

\section{Declaration}

The study was retrospective. All patients were informed (leaflets, posters in several local languages) that the data and analysis results may be used in research and that they had a right to refuse.

\section{Financial support}

This work has benefited from an "Investissement d'Avenir" grant managed by Agence Nationale de la Recherche (CEBA, ANR-10-LABX-25-01).

\section{Author details}

${ }^{1}$ Equipe EA3593 Ecosystemes Amazoniens et Pathologie Tropicale, Université de la Guyane, Campus Saint Denis, Avenue d'Estrées, 97300 Cayenne, French Guiana. ${ }^{2}$ Centre d'Investigation Clinique Epidémiologie Clinique Antilles Guyane CIC CIE 1424, Cayenne General Hospital, 97300 Cayenne, French Guiana. ${ }^{3}$ Laboratoire Associé - Centre National de Référence Leishmania, Laboratoire Hospito-Universitaire de Parasitologie Mycologie, Cayenne General Hospital, 97300 Cayenne, French Guiana. ${ }^{4}$ Department of Dermatology, Cayenne General Hospital, 97300 Cayenne, French Guiana, France. 
Received: 7 December 2016 Accepted: 21 February 2017 Published online: 28 February 2017

\section{References}

1. WHO. Neglected tropical diseases. http://www.who.int/neglected_diseases/ diseases/en/. Accessed 10 Jan 2017

2. Desjeux P. Worldwide increasing risk factors for leishmaniasis. Med Microbiol Immunol. 2001;190(1-2):77-9.

3. Desjeux P. Leishmaniasis: current situation and new perspectives. Comp Immunol Microbiol Infect Dis. 2004;27(5):305-18.

4. Alvar J, Velez ID, Bern C, Herrero M, Desjeux P, Cano J, Jannin J, den Boer M. WHO leishmaniasis control team. Leishmaniasis worldwide and global estimates of its incidence. PLoS One. 2012:7(5):e35671.

5. Floch $\mathrm{H}$. Notes and discussions on forest leishmaniasis in French Guiana Archives de l'Institut Pasteur de la Guyane Française et de l'Inini. 1954; 15(330):1-8

6. Carme B, Aznar C, Pradinaud R. Absence of a proven resurgence of Chagas disease or cutaneous leishmaniasis in French Guiana over the last two decades. Ann Trop Med Parasitol. 2001;95(6):623-5.

7. Dedet JP. Cutaneous leishmaniasis in French Guiana: a review. Am J Trop Med Hyg. 1990;43(1):25-8.

8. Dedet JP, Carme B, Desbois N, Bourdoiseau G, Lachaud L, Pratlong F. Epidemiology of autochthonous leishmaniases in France. Presse Med. 2013; 42(11):1469-81.

9. Basset D, Pratlong F, Ravel C, Puechberty YJ, Dereure J, Dedet J. P. Les leishmanioses déclarées en France en 1999. Bull Epidemiol Hebd. 2001:5:19-21.

10. Rotureau B. Ecology of the leishmania species in the Guianan ecoregion complex. Am J Trop Med Hyg. 2006;74(1):81-96.

11. Rotureau B, Catzeflis F, Carme B. Absence of leishmania in Guianan bats. Am J Trop Med Hyg. 2006;74(2):318-21.

12. Couppie P, Clyti E, Sainte-Marie D, Dedet JP, Carme B, Pradinaud R. Disseminated cutaneous leishmaniasis due to Leishmania guyanensis: case of a patient with 425 lesions. Am J Trop Med Hyg. 2004;71(5):558-60.

13. Raccurt CP, Pradinaud R, Couppie P, Moreau B, Pratlong F, Dedet JP, Cotellon P, Juminer B, Sainte-Marie D. Leishmania (Viannia) braziliensis Vianna, 1911 in French Guiana. Clinical, therapeutic and epidemiological considerations in the ninth human diagnosed case. Bull Soc Pathol Exot. 1996:89(5):341-4.

14. Simon S, Veron V, Carme B. Leishmania spp. identification by polymerase chain reaction-restriction fragment length polymorphism analysis and its applications in French Guiana. Diagn Microbiol Infect Dis. 2010;66(2):175-80

15. Dedet JP, Esterre P, Pradinaud R. Individual clothing prophylaxis of cutaneous leishmaniasis in the Amazonian area. Trans R Soc Trop Med Hyg. 1987;81(5):748

16. Kato H, Watanabe J, Mendoza Nieto I, Korenaga M, Hashiguchi Y. Leishmania species identification using FTA card sampling directly from patients' cutaneous lesions in the state of Lara, Venezuela. Trans R Soc Trop Med Hyg. 2011;105(10):561-7.

17. Ramirez JD, Hernandez C, Leon CM, Ayala MS, Florez C, Gonzalez C. Taxonomy, diversity, temporal and geographical distribution of cutaneous leishmaniasis in Colombia: a retrospective study. Sci Rep. 2016;6:28266.

18. Agudelo LA, Uribe J, Sierra D, Ruiz F, Velez ID. Presence of American cutaneous Leishmaniasis vectors surrounding the city of Medellin, Colombia. Mem Inst Oswaldo Cruz. 2002:97(5):641-2.

19. Desjeux P, Dedet JP. Isoenzyme characterization of 112 Leishmania isolates from French Guiana. Trans R Soc Trop Med Hyg. 1989:83(5):610-2.

20. Dedet JP, Pradinaud R, Gay F. Epidemiological aspects of human cutaneous leishmaniasis in French Guiana. Trans R Soc Trop Med Hyg. 1989:83(5):616-20.

21. Costa PL, Dantas-Torres F, da Silva FJ, Guimaraes VC, Gaudencio K, BrandaoFilho SP. Ecology of Lutzomyia longipalpis in an area of visceral leishmaniasis transmission in north-eastern Brazil. Acta Trop. 2013:126(2):99-102.

22. Fernandez MS, Lestani EA, Cavia R, Salomon OD. Phlebotominae fauna in a recent deforested area with American tegumentary leishmaniasis transmission (Puerto Iguazu, Misiones, Argentina): seasonal distribution in domestic and peridomestic environments. Acta Trop. 2012;122(1):16-23.

23. Oceanic Niño Index. El Niño and La Niña years and intensities. http:// ggweather.com/enso/oni.htm. Accessed 10 Jan 2017.

24. Roger A, Nacher M, Hanf M, Drogoul AS, Adenis A, Basurko C, Dufour J, Sainte Marie D, Blanchet D, Simon S, Carme B, Couppie P. Climate and leishmaniasis in French Guiana. Am J Trop Med Hyg. 2013;89(3):564-9.
25. Cardenas R, Sandoval CM, Rodriguez-Morales AJ, Franco-Paredes C. Impact of climate variability in the occurrence of leishmaniasis in northeastern Colombia. Am J Trop Med Hyg. 2006;75(2):273-7.

26. Franke CR, Ziller M, Staubach C, Latif M. Impact of the El Nino/Southern Oscillation on visceral leishmaniasis, Brazil. Emerg Infect Dis. 2002;8(9):914-7.

27. Chaves LF, Pascual M. Climate cycles and forecasts of cutaneous leishmaniasis, a nonstationary vector-borne disease. PLoS Med. 2006;3(8):e295.

28. Feliciangeli MD, Rabinovich J. Abundance of Lutzomyia ovallesi but not Lu. gomezi (Diptera: Psychodidae) correlated with cutaneous leishmaniasis incidence in north-central Venezuela. Med Vet Entomol. 1998;12(2):121-31.

29. Hanf M, Adenis A, Nacher M, Carme B. The role of El Nino Southern Oscillation (ENSO) on variations of monthly Plasmodium falciparum malaria cases at the Cayenne General Hospital, 1996-2009, French Guiana. Malar J. 2011;10:100-2875-10-100

\section{Submit your next manuscript to BioMed Central and we will help you at every step:}

- We accept pre-submission inquiries

- Our selector tool helps you to find the most relevant journal

- We provide round the clock customer support

- Convenient online submission

- Thorough peer review

- Inclusion in PubMed and all major indexing services

- Maximum visibility for your research

Submit your manuscript at www.biomedcentral.com/submit
) Biomed Central 